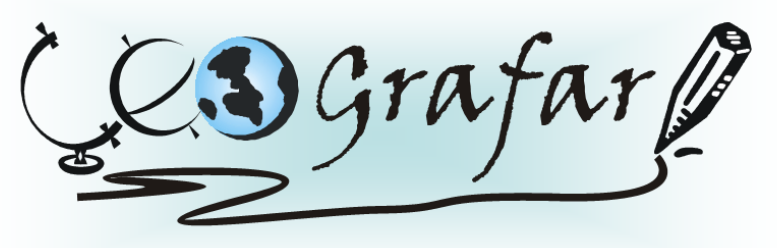

Revista Eletrônica do Programa de Pós-Graduação em Geografia - UFPR

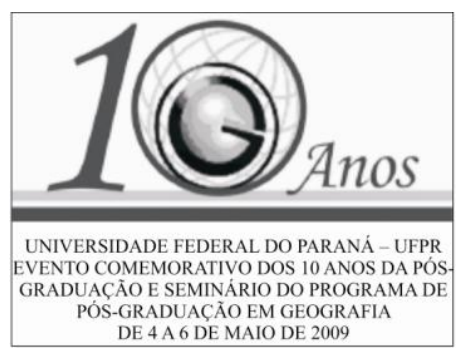

\title{
SUSTENTABILIDADE DA NATUREZA SOB A ÓTICA MUNICIPAL: O CASO DE MARECHAL CÂNDIDO RONDON-PR
}

\author{
MARISTELA MORESCO MEZZOMO ${ }^{1}$ \\ JOÃO CARLOS NUCCI ${ }^{2}$
}

\section{LINHA DE PESQUISA: PAISAGEM E ANÁLISE AMBIENTAL}

As discussões em busca de soluções que permitam com que o atual modelo de desenvolvimento econômico prossiga mesmo diante dos problemas ambientais, tem se pautado nos últimos anos no chamado desenvolvimento sustentável. Este conceito envolve uma gama de elementos que permitem várias interpretações e promovem muitos questionamentos.

Entre as diversas interpretações para sustentabilidade a compreensão aqui apresentada se refere a sustentabilidade multidimensional, entendida a partir de diferentes dimensões: social, cultural, econômica, política e da natureza. O estudo da sustentabilidade multidimensional teria como ponto de partida a dimensão da natureza, já que esta se constitui como um suporte para que as demais dimensões se desenvolvam (Fávero, 2007). Entendida assim como suporte, a sustentabilidade da natureza vem ao encontro dos interesses do planejamento da paisagem, que visa o entendimento da estrutura e organização da paisagem como forma de compreensão do seu funcionamento. Este entendimento permite o reconhecimento das condições da paisagem, contribuindo na elaboração e aplicação de projetos de planejamento em bacias hidrográficas, territórios ou municípios.

No que se refere ao planejamento da paisagem de uma unidade político-administrativa como os municípios, há, aparentemente, uma dificuldade no que tange o tratamento da paisagem dentro dos limites territoriais. Esta dificuldade é oriunda do fato de que os elementos componentes da paisagem não seguem os limites (im) postos. Neste sentido, questiona-se como os municípios pensam e tratam a sustentabilidade da natureza, uma vez

\footnotetext{
${ }^{1}$ mary_mezo@hotmail.com

${ }^{2}$ Professor orientador
} 
que os limites territoriais se tornam, por vezes, os próprios limites do planejamento? Como a legislação aborda a sustentabilidade diante das divisões municipais? Como os municípios planejam a paisagem diante destas situações? Seria possível os municípios terem sustentabilidade da natureza?

Diante destas inquietações, a busca pelas respostas tem como objeto de estudo o município de Marechal Cândido Rondon, localizado na região oeste do estado do Paraná. A partir da discussão teórica entorno de conceitos como sustentabilidade, sustentabilidade multidimensional, sustentabilidade da natureza, paisagem, planejamento da paisagem e planejamento municipal, e com alguns referenciais teóricos como Gomez Orea (1978), Bolós (1992), Diegues (1992), Monteiro (2000), Leff (2000; 2001), Nucci (2001), (Franco 2001), Mateo Rodrigues et al. (2004), Bellen (2005), Fávero (2007), entre outros, o intuito é compreender se há sustentabilidade da natureza no município e como o mesmo prevê e trata a questão de sustentabilidade nos seus projetos de planejamento da paisagem.

Palavras-chave: Sustentabilidade, Paisagem, Planejamento.

\section{REFERÊNCIAS}

BELLEN, H. M. Indicadores de Sustentabilidade: uma análise comparativa. Rio de Janeiro: Editora FGV, 2005. 256p.

BOLÓS, M. de (org.) Manual de Ciencia del Paisaje: teoría, métodos y aplicaciones. Barcelona: Masson, S. A, 1992. 273p.

DIEGUES, A. C. S. Desenvolvimento sustentável ou sociedades sustentáveis: da crítica dos modelos aos novos paradigmas. São Paulo em Perspectiva, vol. 6/1-2, São Paulo> Fundação SEADE, 1992. p. 22-29.

FÁVERO, O. A. Paisagem e sustentabilidade na bacia hidrográfica do rio Sorocaba - SP. Tese (Doutorado em Geografia Humana). 312f. FFLCH/DG. São Paulo, 2007.

FRANCO, M.A.R. Planejamento Ambiental para Cidade Sustentável..Rio de Janeiro: Edifurb, 2ed.2001.

LEFF, E. Ecologia, Capital e Cultura: racionalidade ambiental, democracia participativa, e desenvolvimento sustentável. Blumenau: Editora da FURB, 2000. 381p. (Coleção Sociedade e Ambiente 5).

LEFF, E. Epistemologia Ambiental. São Paulo: Cortez, 2001 (b). 240p.

MATEO RODRIGUEZ, J. M.; SILVA, E. V.; CAVALCANTI, A. P. B. Geoecologia das Paisagens: uma visão geossistêmica da análise ambiental. Fortaleza: Editora UFC, 2004. 
MONTEIRO, C.A.F. Geossistemas: a história de uma procura. São Paulo: Contexto, 2000, $128 \mathrm{p}$.

NUCCI, J. C. Qualidade ambiental e adensamento urbano: um estudo de ecologia e planejamento da paisagem aplicado ao distrito de Santa Cecília (MSP). São Paulo: HUMANISTAS/FAPESP, 2001. 236p.

STAHEL, A. W. Capitalismo e Entropia: os aspectos ideológicos de uma contradição e a busca de alternativas sustentáveis. In: CAVALCANTI, C. (org.) Desenvolvimento e Natureza: Estudos para uma Sociedade Sustentável. São Paulo: Cortez; Recife: Fundação Joaquim Nabuco, 1995. p. 104-127. 